\title{
Investigation of Infrared and Raman Spectra of $\mathrm{TeO}_{2}-\mathrm{Nb}_{2} \mathrm{O}_{5}-\mathrm{TiO}_{2}$ Glasses
}

\author{
İ. KABALCI ${ }^{a, *}$ AND H. GÖKÇE ${ }^{b}$ \\ ${ }^{a}$ Department of Physics, Education Faculty, Harran University, Sanliurfa, Turkey \\ ${ }^{b}$ Department of Metallurgical and Materials Engineering, İstanbul Technical University \\ Maslak, 34469 İstanbul, Turkey
}

\begin{abstract}
X-ray diffraction, infrared (IR), Raman spectroscopy and scanning electron microscope techniques have been used to investigate the microstructural properties of the glass materials. In this work, a new type of tellurite based optical glasses with $\mathrm{TeO}_{2} / \mathrm{Nb}_{2} \mathrm{O}_{5} / \mathrm{TiO}_{2}$ for different $x \mathrm{Nb}_{2} \mathrm{O}_{5}(x=5,10,15$, and $20 \mathrm{~mol} . \%)$ glass compositions at constant $5 \mathrm{~mol} \% \mathrm{TiO}_{2}$ ratio were prepared. The effect of $\mathrm{Nb}_{2} \mathrm{O}_{5}$ contents on the structural unit of $(95-x) \mathrm{TeO}_{2}-$ $(x) \mathrm{Nb}_{2} \mathrm{O}_{5}-5 \mathrm{TiO}_{2}$ glass network, and the intensity ratios of the Raman peaks were investigated. The results indicate that for different $\mathrm{Nb}_{2} \mathrm{O}_{5}$ content 5 to 20 mol.\% in the glass system, three vibrational peaks around 650 , 800, and $920 \mathrm{~cm}^{-1}$ which correspond to the structural bonding of the glass were observed in the range of $500-2000 \mathrm{~cm}^{-1}$ for the IR spectra. Furthermore, from the Raman results a structural evolution was determined with the number of structural units such as $\left[\mathrm{NbO}_{6}\right]^{7-}, \mathrm{TeO}_{3+1}$ (polyhedra), $\mathrm{TeO}_{4}$ (trigonal bipyramids), $\mathrm{TeO}_{3}$ (trigonal pyramids) or $\mathrm{TeO}_{3+1}$ (polyhedra), and $\left[\mathrm{NbO}_{4}\right]^{3-}$ for this ternary glass system.
\end{abstract}

DOI: 10.12693 /APhysPolA.125.877

PACS: 42.70.Ce; 61.05.Cp; 82.80Gk; 78.30.Ly

\section{Introduction}

The successful progress of photonics and its applications have been accelerated by discovery of new materials. Tellurite- $\left(\mathrm{TeO}_{2}\right)$ based glasses have received great attention because of their excellent physical properties, chemical durability, and thermal stability for their possible use in the fiber optic amplifier, and fiber laser applications [1-3]. Furthermore, tellurite based glasses show interesting physical and structural properties when compared to silicate, borate, and phosphate glasses, such as high dielectric constant, high refractive index, low phonon energy, and low melting temperature $[4,5]$. It is reported that the third order non-linear optical susceptibilities of $\mathrm{TeO}_{2}$ based glasses were several orders of magnitude larger than that of conventional silicate and borate glasses and were applied to nonlinear optical devices, like optical wavelength converter, optical switching, and Raman amplification [6-8]. Moreover, $\mathrm{Nb}_{2} \mathrm{O}_{5}$ glass modifier can improve properties of optical nonlinearity, vitrification and glass stability [9-11]. In order to determine this correlation between the physical properties and their atomic arrangements, microstructural studies on several $\mathrm{TeO}_{2}$-based glass systems were performed by many researchers including glassy network formers and modifiers as $\mathrm{MO}-\mathrm{Nb}_{2} \mathrm{O}_{5}-\mathrm{TeO}_{2}(\mathrm{M}=\mathrm{Zn}, \mathrm{Mg}, \mathrm{Ca}, \mathrm{Sr}, \mathrm{Ba}), \mathrm{TeO}_{2}-$ $\mathrm{PbF}_{2}, \mathrm{TeO}_{2}-\mathrm{K}_{2} \mathrm{O}, \mathrm{TeO}_{2}-\mathrm{Nb}_{2} \mathrm{O}_{5}-\mathrm{Bi}_{2} \mathrm{O}_{3}$ glasses [11-15]. However, any detailed microstructural characterization on the $\mathrm{TeO}_{2}-\mathrm{Nb}_{2} \mathrm{O}_{5}-5 \mathrm{TiO}_{2}$ ternary glasses has not yet been reported in the literature, except that of Villegas and Fernandez Navarro [16] who worked out the opti-

\footnotetext{
*corresponding author; e-mail: kabalci@harran.edu.tr
}

cal and structural properties using optical absorption, infrared, and Raman spectra of the binary $\left(\mathrm{TeO}_{2}-\mathrm{Nb}_{2} \mathrm{O}_{5}\right)$ and ternary $\left(\mathrm{TeO}_{2}-\mathrm{Nb}_{2} \mathrm{O}_{5}-\mathrm{TiO}_{2}\right)$ glass samples for 5 , and $10 \mathrm{~mol} . \% \mathrm{TiO}_{2}$ contents.

Tellurium oxide- $\left(\mathrm{TeO}_{2}\right)$ has long been studied as a good glass network former, but it is not able to form a glass structure by itself, but it forms glasses easily with the addition of elements such as $\mathrm{Nb}_{2} \mathrm{O}_{5}, \mathrm{PbF}_{2}, \mathrm{ZnO}$, as modifiers $[14,17]$. Mallawany and Silva et al. [18, 19] reported that $\mathrm{TeO}_{2}$ crystallizes in two different phases called $\alpha-\mathrm{TeO}_{2}$ (paratellurite, tetragonal) and $\beta-\mathrm{TeO}_{2}$ (tellurite, orthorhombic), which have been known to be stable phases [8]. Additionally, Mirgorodsky et al. [20] and Blanchandin et al. [21] pointed out that $\mathrm{TeO}_{2}$ may also form two metastable crystalline phases called $\gamma-\mathrm{TeO}_{2}$ (orthorhombic) and $\delta-\mathrm{TeO}_{2}$ (cubic). In order to understand the thermal stability against crystallization, structural behavior in the mechanism in the glass transition region is important as a new type of nonlinear materials $[20,21]$.

In this research, we have realized the microstructural properties of $(95-x) \mathrm{TeO}_{2}-x \mathrm{Nb}_{2} \mathrm{O}_{5}-5 \mathrm{TiO}_{2}(x=5,10$, 15 , and $20 \mathrm{~mol} . \%$ ) glasses by X-ray diffraction (XRD), infrared and Raman spectroscopy. Due to the relationship between the coordination geometry of the Te atoms and compositions, addition of $\mathrm{Nb}_{2} \mathrm{O}_{5}, \mathrm{~K}_{2} \mathrm{O}, \mathrm{WO}_{3}$ glass modifiers changes the coordination of $\mathrm{Te}$ from $\mathrm{TeO}_{4}$ trigonal bipyramid (tbp) to a $\mathrm{TeO}_{3}$ trigonal bipyramid (tp) through intermediate polyhedral $\mathrm{TeO}_{3+1}$ unit [22, 23]. Therefore, transition between the $\mathrm{TeO}_{4}$ and $\mathrm{TeO}_{3}$ microstructures is stressed by the shortening of one of the axial bond while one equatorial bond gets longer $\left(\mathrm{TeO}_{3+1}\right.$ polyhedra) when the glass modifier increases $[24,25]$. In order to explain more about this relationship between the 
microstructure and glass modifiers, we have carried out the systematic studies on $\mathrm{TeO}_{2}$ network with different $\mathrm{Nb}_{2} \mathrm{O}_{5}$ content $(x=5,10,15$, and 20 mol. $\%$ ).

\section{Experimental}

The $(95-x) \mathrm{TeO}_{2}-x \mathrm{Nb}_{2} \mathrm{O}_{5}-5 \mathrm{TiO}_{2}(x=5,10,15$, and 20 mol.\%) glasses were prepared using optical $\mathrm{TeO}_{2}$ crystalline powders. All the chemical materials were reagent grade commercial powders with purity higher than $99.99 \%$. Now hereafter the glass compositions are referred to as TNT1, TNT2, TNT3, and TNT4 for the $x=5,10,15$, and $25 \mathrm{~mol} . \% x \mathrm{Nb}_{2} \mathrm{O}_{5}$ contents, respectively. Batches of $7 \mathrm{~g}$ in size were thoroughly mixed and melted in air using a platinum crucible with a closed lid in an electrically heated furnace at $850^{\circ} \mathrm{C}$ for TNT1, TNT2, TNT3 samples, but TNT4 sample was melted at $990^{\circ} \mathrm{C}$ for $60 \mathrm{~min}$. The melts were then removed from the furnace at above temperatures and quenched in air by pressing between two rectangular graphite slabs at room temperature. Differential thermal analysis (DTA) scans of as-cast $x \mathrm{Nb}_{2} \mathrm{O}_{5}, x=5,10,15$, and 20 mol.\% glasses were carried out in a TA Q600 DTA/TGA/DSC (Newcastle DE). The DTA scans were recorded 3 to $10 \mathrm{mg}$ as cast glass specimens that were recorded with heating rate of $20^{\circ} \mathrm{C} / \mathrm{min}$ between 20 and $800{ }^{\circ} \mathrm{C}$ temperatures in a platinum crucible.

The XRD technique was performed on both as-cast glasses, and heat treated glass ceramics using a Rigaku X-ray diffractometer, Ultimate III, to investigate the glass structure and identify the crystallized phases. All traces were recorded using $\mathrm{Cu} K_{\alpha}$ radiation, and the diffractometer setting in the $2 \theta$ range from 10 to $90^{\circ}$ by changing the $2 \theta$ with a step size 0.02 . All of the samples were ground to fine powders for investigation, and Eva Software (Bruker) was used to label peaks and then distinguish the crystalline phases existing in the sample. After obtaining the heat treated glasses, the International Center for Diffraction Data files were used to identify the crystallized phases by comparing the intensities and the peak positions.

The Fourier transform (FT) infrared spectra were recorded with Perkin Elmer FT-IR spectrometer in the $1200-400 \mathrm{~cm}^{-1}$ range, by using the $\mathrm{KBr}$ pellets (FT-IR Accessory Hydraulic press) technique. The structure of these tellurite glasses was measured by FT Raman spectrophotometer (Fourier transform) (Digilab FTS 7000 Series) within the range of $0-1200 \mathrm{~cm}^{-1}$. The digital intensity data was recorded at intervals of $1 \mathrm{~cm}^{-1}$. A Nd:YAG laser system operating at $1064 \mathrm{~nm}$ was used as the excitation source to determine the Raman spectrum, and the specimen excited with a power level of about $500 \mathrm{~mW}$. The scattered radiation was detected by cooling Ge detector with a spectral resolution of $8 \mathrm{~cm}^{-1}$.

SEM was carried out both in a ZEISS EVO'50 and equipped with energy dispersive spectrometer attachment Bruker EDAX. For the SEM investigations, to investigate the crystallization processes and to determine the crystallization mechanism both on the surface, and the cross-sections of the glass samples, all the samples were etched with $5 \%$ HF solution in a $30 \mathrm{~s}$.

\section{Results and discussion}

DTA investigations have been conducted on the as-cast glass samples for TNT1, TNT2, TNT3, and TNT4 to understand the effect of $\mathrm{Nb}_{2} \mathrm{O}_{5}$ glass modifiers on the glass transition, $T_{\mathrm{g}}$, crystallization, $T_{\mathrm{c}}$, and the melting temperatures, $T_{\mathrm{m}}$. The respective DTA plots are given in Fig. 1. Glass transition, $T_{\mathrm{g}}$, crystallization, $T_{\mathrm{c} 1}, T_{\mathrm{c} 2}$, and melting, $T_{\mathrm{m}}$, temperatures are marked on the DTA plots of the respective glasses. As can be seen from Fig. 1 and Table, incorporation of $\mathrm{Nb}_{2} \mathrm{O}_{5}$ contents into the glass network increases the glass transition and melting temperatures. Crystallization temperatures are marked by exothermic peak referring to crystallization processes for each glass samples and the first two glass samples for TNT1 and TNT2 have two exothermic peaks marked as $T_{\mathrm{c} 1}$ and $T_{\mathrm{c} 2}$, the other two samples for TNT3 and TNT4 have only just one exothermic peak.

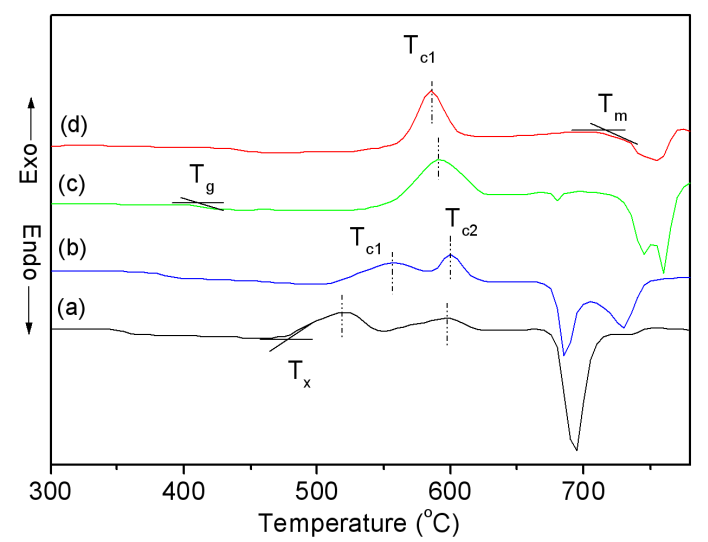

Fig. 1. DTA scans of the as-cast: (a) TNT1, (b) TNT2, (c) TNT3, and (d) TNT4 optical glasses with different heating rates of $20^{\circ} \mathrm{C} / \mathrm{min}$.

TABLE

The glass transition $\left(T_{\mathrm{g}}\right)$, peak crystallization $\left(T_{\mathrm{c}}\right)\left(T_{\mathrm{c} 1}\right.$ and $T_{\mathrm{c} 2}$ show the first and second exothermic peak crystallization, respectively), onset $\left(T_{x}\right)$, melting $\left(T_{\mathrm{m}}\right)$ temperatures and Hruby parameter $\left(K_{\mathrm{g} 1}\right)$ of the TNT1, TNT2, TNT3, and TNT4 glass detected during the DTA scans*.

\begin{tabular}{c|c|c|c|c|c|c|c}
\hline \hline \multirow{2}{*}{$\begin{array}{c}\text { Glass } \\
\text { samples }\end{array}$} & \multirow{2}{*}{$\begin{array}{c}T_{\mathrm{g}} \\
\left( \pm 3^{\circ} \mathrm{C}\right)\end{array}$} & \multicolumn{2}{|c|}{$\begin{array}{c}T_{\mathrm{c}} \\
\left( \pm 3^{\circ} \mathrm{C}\right)\end{array}$} & $\begin{array}{c}T_{x} \\
\left( \pm 3^{\circ} \mathrm{C}\right)\end{array}$ & $\begin{array}{c}T_{\mathrm{m}} \\
\left( \pm 3{ }^{\circ} \mathrm{C}\right)\end{array}$ & $\begin{array}{c}\Delta T \\
\left(T_{x}-T_{\mathrm{g}}\right) \\
{\left[{ }^{\circ} \mathrm{C}\right]}\end{array}$ & $K_{\mathrm{g} 1}$ \\
\cline { 3 - 4 } TNT1 & 355 & 490 & 565 & 455 & 690 & 100 & 0.43 \\
TNT2 & 390 & 545 & 590 & 495 & 685 & 105 & 0.55 \\
TNT3 & 420 & 575 & - & 515 & 745 & 95 & 0.41 \\
TNT4 & 450 & 570 & - & 510 & 755 & 60 & 0.24 \\
\hline
\end{tabular}

* The $T_{\mathrm{g}}$ values are measured at the mid-point between the onset and the minimum temperatures of the glass transition endotherm and the $T_{\mathrm{c}}$ are measured at the peak of the glass transition exotherm during the DTA scans.

The thermal stability of the prepared glass samples is important parameter related with nucleation of the structures. The thermal stability was determined by calculating glass-forming tendency $\left(K_{\mathrm{g} 1}\right)$ by using the glass transition $\left(T_{\mathrm{g}}\right)$, onset peak crystallization $\left(T_{x}\right)$, and melting temperatures $\left(T_{\mathrm{m}}\right)[26]$. The glass stability $(\Delta T)$ is a 
measure of the glass thermal stability, and can be determined by the difference between the first onset crystallization temperature $\left(T_{x}\right)$ and the glass transition temperature $\left(T_{\mathrm{g}}\right)$. As seen from Table, the glass forms tendency for the TNT2 sample higher than the other glass samples, and also shows good thermal stability. Easy glass forming tendency calculated using the Hruby parameter, $K_{\mathrm{g} 1}[27]$, is given by

$$
K_{\mathrm{g} 1}=\frac{T_{x}-T_{\mathrm{g}}}{T_{\mathrm{m}}-T_{x}} .
$$

XRD technique has been widely used to identify the crystalline phases in heat treated glasses. On the basis of DTA plots given in Fig. 1, XRD measurements were performed to determine the crystallizing phases in the heat treated structures for all the samples.

Figures 2-4 reported here show the XRD patterns of the samples together with the $\alpha-\mathrm{TeO}_{2}, \mathrm{Nb}_{2} \mathrm{Te}_{4} \mathrm{O}_{13}$, and $\mathrm{TiTe}_{3} \mathrm{O}_{8}$ crystalline phases.

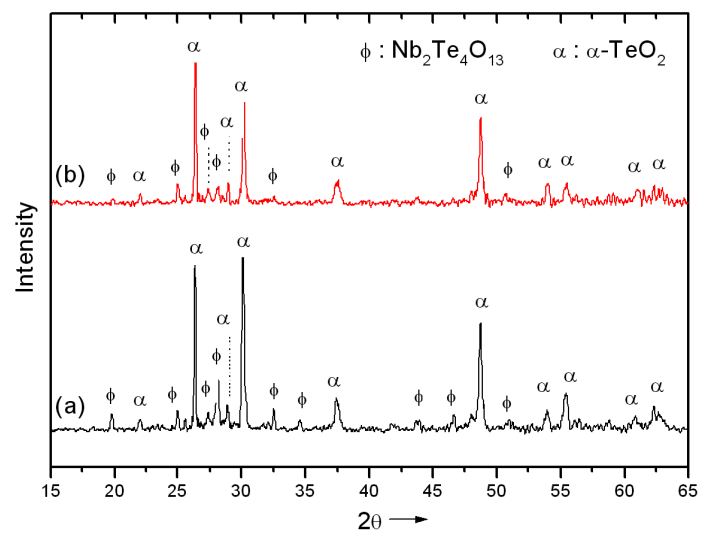

Fig. 2. XRD scans taken from (a) for the first exotherm and (b) for the second exotherm of TNT1 samples heat treated at $550^{\circ} \mathrm{C}$ and $630^{\circ} \mathrm{C}$, respectively.

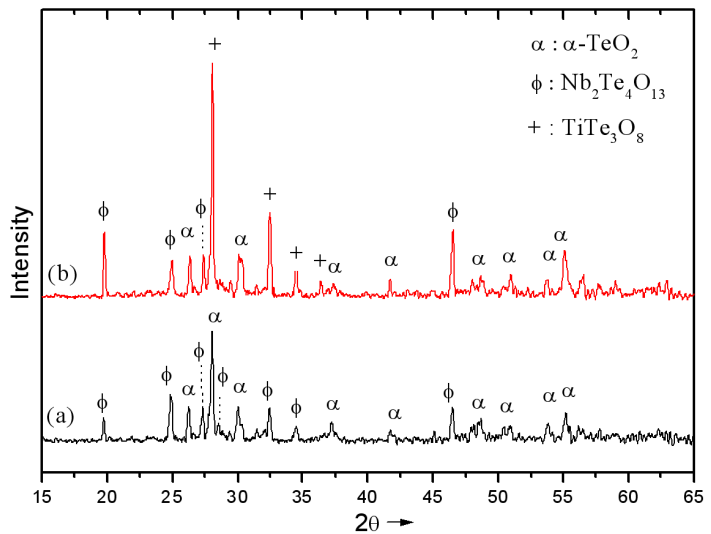

Fig. 3. XRD scans taken (a) for the first exotherm and (b) for the second exotherm of TNT2 samples heat treated at $585^{\circ} \mathrm{C}$ and $630^{\circ} \mathrm{C}$, respectively.

Figure 2a,b is the XRD patterns taken from the heat treated samples for the first and second exotherm of the

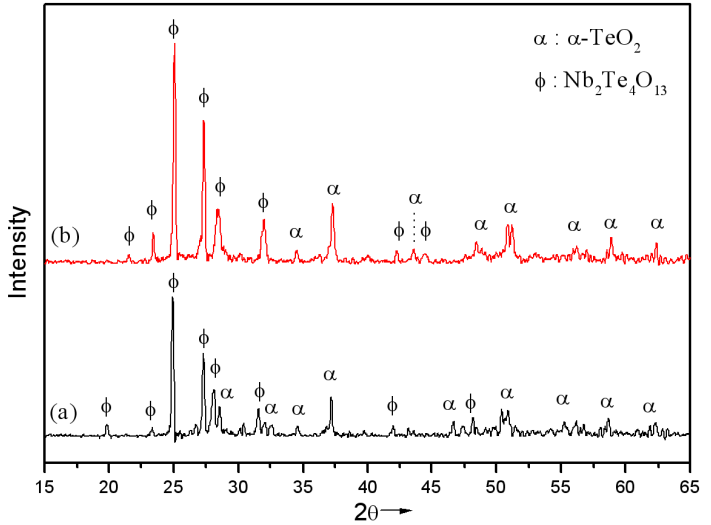

Fig. 4. XRD scans taken (a) TNT3, (b) TNT4 samples heat treated at $630{ }^{\circ} \mathrm{C}$ and $620^{\circ} \mathrm{C}$, respectively.

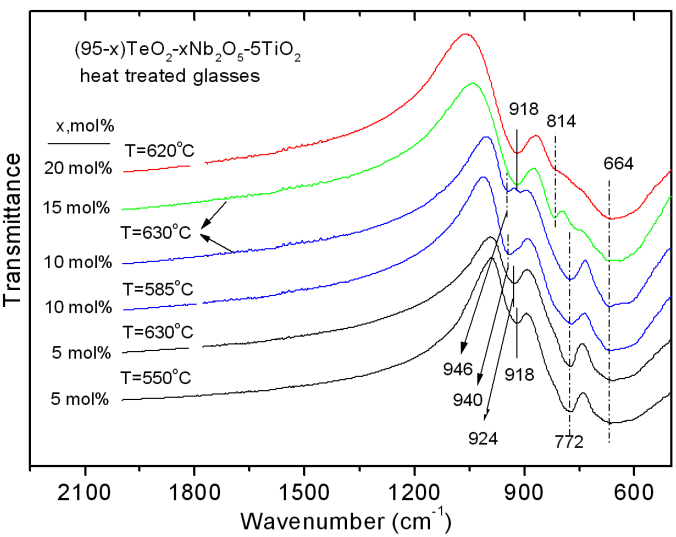

Fig. 5. FT-infrared spectra of the TNT1, TNT2, TNT3, and TNT4 samples.

DTA scans for the TNT1 sample heat treated at 550 and $630^{\circ} \mathrm{C}$ for $60 \mathrm{~min}$, respectively. As seen from Fig. 2a,b, when temperature increases from 550 to $630^{\circ} \mathrm{C}$, some of the XRD peaks of the $\mathrm{Nb}_{2} \mathrm{Te}_{4} \mathrm{O}_{13}$ vanish.

The XRD pattern of TNT2 glass samples recorded after the sample was anealed at 585 and $630^{\circ} \mathrm{C}$ for $60 \mathrm{~min}$ is given in Fig. 3a,b. As seen from Fig. 3a,b, $\alpha-\mathrm{TeO}_{2}$, $\mathrm{Nb}_{2} \mathrm{Te}_{4} \mathrm{O}_{13}$, and $\mathrm{TiTe}_{3} \mathrm{O}_{8}$ co-existing in the matrix crystalline phases were detected. For the same sample, increasing temperature from 585 to $630^{\circ} \mathrm{C}$ for the TNT2, the XRD peaks of the $\alpha-\mathrm{TeO}_{2}$ decrease, the peaks of the $\mathrm{Nb}_{2} \mathrm{Te}_{4} \mathrm{O}_{13}$ do not change, but new crystalline phase of $\mathrm{TiTe}_{3} \mathrm{O}_{8}$ arises dominantly.

As can be seen from Fig. 4a,b patterns of the samples TNT3 and TNT4 predict that the crytalline phases are $\alpha-\mathrm{TeO}_{2}$ and $\mathrm{Nb}_{2} \mathrm{Te}_{4} \mathrm{O}_{13}$. It may be concluded from Fig. 4a,b that the peaks of the $\mathrm{TiTe}_{3} \mathrm{O}_{8}$ crystalline phase vanish for samples TNT3 and TNT4 at nearly $620^{\circ} \mathrm{C}$. However, the peaks of the $\mathrm{Nb}_{2} \mathrm{Te}_{4} \mathrm{O}_{13}$ phase are seen more dominant than the peaks of $\alpha-\mathrm{TeO}_{2}$ phase.

The FT infrared spectra of the samples of TNT1, TNT2, TNT3, and TNT4 were recorded in the frequency region 500 to $2000 \mathrm{~cm}^{-1}$ and are shown in Fig. 5. From 
literature, tellurite glasses show $\alpha-\mathrm{TeO}_{2}$ (paratellurite) crystallization which is formed by $\left[\mathrm{TeO}_{4}\right]$ trigonal bipyramids (tbp) [11]. In tellurite based glasses, when glass modifiers incorporated into the glass network which becomes more open and non-bridging oxygens were created by considering the $\left[\mathrm{TeO}_{3+1}\right]$ and $\left[\mathrm{TeO}_{3}\right]$ structural forms. In ternary $\mathrm{TeO}_{2}-x \mathrm{Nb}_{2} \mathrm{O}_{5}-5 \mathrm{TiO}_{2}$ glass systems, incorporation of $\mathrm{Nb}_{2} \mathrm{O}_{5}$ contents causes an important structural change in the telluride glass network. The absorption band at $626-650 \mathrm{~cm}^{-1}$ was attributed to $\mathrm{TeO}_{4}$ trigonal bipyramids (tbp), which shifted to higher frequency when increased $\mathrm{Nb}_{2} \mathrm{O}_{5}$ contents in the glass network from 5 to $20 \mathrm{~mol} \%$. The absorption band at around $800-756 \mathrm{~cm}^{-1}$ shifted to higher frequency by increasing glass modifiers from 50 to $20 \mathrm{~mol} . \%$ and it was assigned to $\mathrm{TeO}_{3}$ or $\mathrm{TeO}_{3+1}$ trigonal pyramids (tp). The band at about $896-920 \mathrm{~cm}^{-1}$ was assigned to $\mathrm{NbO}_{4}$ tetrahedra which were shifted to higher frequency when $\mathrm{Nb}_{2} \mathrm{O}_{5}$ contents increased from 5 to 20 mol.\%. As shown in Fig. 5, from the above explanation, the first absorption band occured at $664 \mathrm{~cm}^{-1}, 772 \mathrm{~cm}^{-1}$ for the TNT1 and TNT2 samples, and last bands $918-946 \mathrm{~cm}^{-1}$ for the 5 to $20 \mathrm{~mol} . \% \mathrm{Nb}_{2} \mathrm{O}_{5}$ contents for the treated glasses from $550-630^{\circ} \mathrm{C}$ crystallization temperatures.

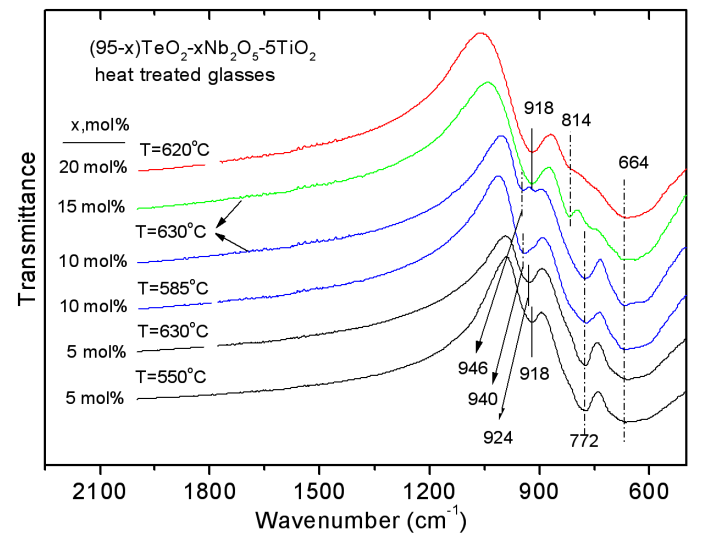

Fig. 6. FT-infrared spectra of the TNT1, TNT2, TNT3, and TNT4 heat treated samples.

Heat treated samples as seen from Fig. 6, the infrared spectra contain the sharp absorption peak at 772,814 , 918 , and $924 \mathrm{~cm}^{-1}$ when compared with Fig. 5. When the absorption band at around $664-772 \mathrm{~cm}^{-1}$ for the 5 and 10 mol.\% $\mathrm{Nb}_{2} \mathrm{O}_{5}$ contents compared with 15 and $20 \mathrm{~mol} . \%$, the latter of the absorption bands disappeared. Villegas et al. [16] reported that the coordination of $\mathrm{Te}$ atoms in $\left[\mathrm{TeO}_{4}\right]$ (tbp) groups changes towards $\left[\mathrm{TeO}_{3}\right]$ (tp) groups due to the fact that $\mathrm{Te}-\mathrm{O}$ bonds in $\left[\mathrm{TeO}_{3}\right]$ polyhedra were shorter, and less polarized.

As a complementary technique to the infrared spectra, Raman scattering spectra obtained using the as-cast glass samples are shown in Fig. 7. Five major Raman bands were obtained at about 265, 450, 661, 800, and $900 \mathrm{~cm}^{-1}$ for these samples at room temperature. The structural units of niobium telluride glasses, coordina-

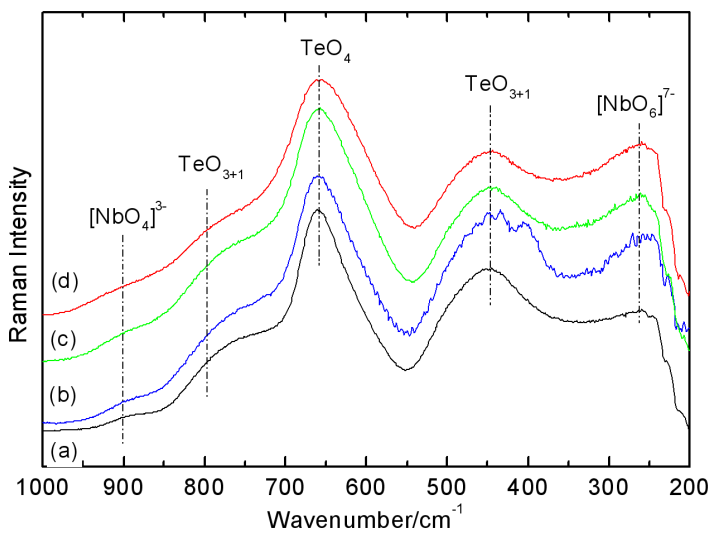

Fig. 7. Raman spectrum for (a) TNT1, (b) TNT2, (c) TNT3, and (d) TNT4 in the as-cast condition.

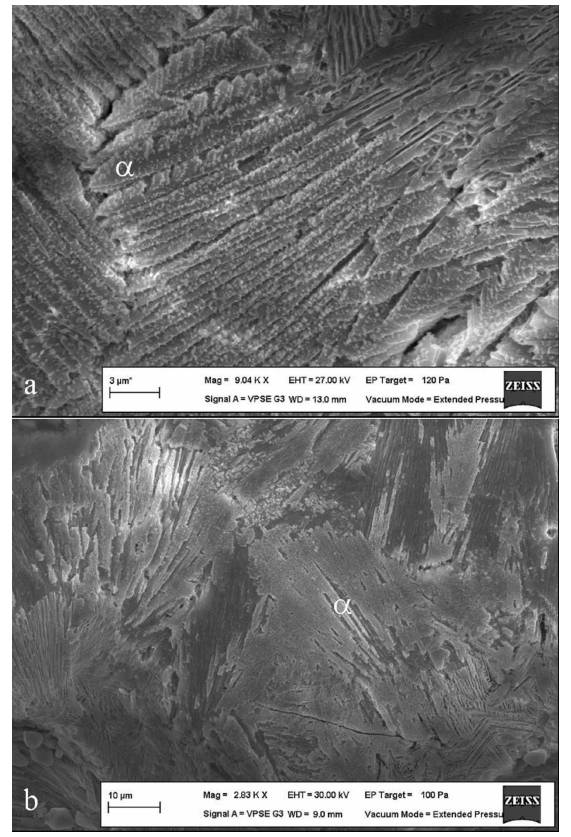

Fig. 8. Typical SEM micrographs taken from the crystalline regions on the (a) surface and the (b) cross-section for the first exotherm of the TNT1 glass samples.

tion polyhedrons comprising $\mathrm{Nb}^{5+}$ or $\mathrm{Te}^{4+}$ cations with oxygen anions, such as $\left[\mathrm{NbO}_{6}\right]^{7-},\left[\mathrm{NbO}_{4}\right]^{3-},\left[\mathrm{NbO}_{4}\right]^{4-}$, $\left[\mathrm{NbO}_{3}\right]^{2-}$, and $\left[\mathrm{TeO}_{3}\right]^{2-}$, and $\left[\mathrm{TeO}_{3+1}\right]^{4-}$ can be taken into consideration $[12,15]$.

Furthermore, SEM investigations were performed on the heat-treated TNT1 glass to identify the morphology of the consequent microstructures after crystallization. The crystalline phases observed in tellurite glasses as $\alpha-\mathrm{TeO}_{2}, \beta-\mathrm{TeO}_{2}, \gamma-\mathrm{TeO}_{2}$, and $\delta-\mathrm{TeO}_{2}$ studied by Tatar et al. [28], and $\mathrm{Oz}_{\mathrm{z}}$ et al. [14] for the $\mathrm{TeO}_{2}-\mathrm{CdF}_{2}-\mathrm{WO}_{3}$ and $(1-x) \mathrm{TeO}_{2}-x \mathrm{~K}_{2} \mathrm{O}$ glass systems. All SEM micrographs were taken in the secondary electron imaging mode. Figure $8 \mathrm{a}, \mathrm{b}$ is the surface and cross-sectional representative SEM micrographs for the first exotherm of TNT1 glass 
sample surfaces, which were heated to $550{ }^{\circ} \mathrm{C}$ followed by quenching. It can be seen that the crystallization structures in this glass composition are needle-like, and the crystals are dominantly oriented in the surface of the glass. EDS analyses taken from the elongated crystalline regions in which from both surface and cross-section (labeled by $\alpha$ in Fig. $8 \mathrm{a}$ and b), (23.25 wt\% Te, 68.89 wt\% O, $6.33 \mathrm{wt} \% \mathrm{Nb}, 1.53 \mathrm{wt} \% \mathrm{Ti})$, and (47.25 wt\% $\mathrm{Te}$, 45.82 wt\% O, 3.94 wt\% Nb, 2.99 wt\% Ti) confirm that the crystalline regions are consistent with mixtures of the $\alpha$ - $\mathrm{TeO}_{2}$ phase with $\mathrm{Nb}_{2} \mathrm{Te}_{4} \mathrm{O}_{13}$, respectively.

\section{Conclusions}

Ternary tellurite based $(95-x) \mathrm{TeO}_{2}-x \mathrm{Nb}_{2} \mathrm{O}_{5}-5 \mathrm{TiO}_{2}$ $(x=5,10,15$, and 20 mol.\%) glasses were prepared by conventional melt-quenching technique in a platinum crucible. All the glass samples were transparent and stable. The XRD patterns of the sample with 5, 15, 20 mol.\% show that the exotherms above the glass transition temperature were associated with the crystallization of $\alpha-\mathrm{TeO}_{2}$ and $\mathrm{Nb}_{2} \mathrm{Te}_{4} \mathrm{O}_{13}$, while the XRD pattern of the sample with 10 mol.\% $\mathrm{Nb}_{2} \mathrm{O}_{5}$ content predicts the existence of $\alpha-\mathrm{TeO}_{2}, \mathrm{Nb}_{2} \mathrm{Te}_{4} \mathrm{O}_{13}$, and $\mathrm{TiTe}_{3} \mathrm{O}_{8}$ crystalline phases.

The influence of the $\mathrm{Nb}_{2} \mathrm{O}_{5}$ contents on glass network has been determined through FT infrared and Raman spectroscopic studies. The IR and Raman spectra of $\mathrm{TeO}_{2}-x \mathrm{Nb}_{2} \mathrm{O}_{5}-5 \mathrm{TiO}_{2}$ glasses reveal that the glass network consists of $\left[\mathrm{NbO}_{6}\right]^{7-}, \mathrm{TeO}_{4}, \mathrm{TeO}_{3}, \mathrm{TeO}_{3+1}$, $\left[\mathrm{NbO}_{4}\right]^{3-}$ structural units.

Moreover, SEM/EDS investigations of the microstructural and morphological properties of the samples reveal distribution of the chemical compositions parallel to the crystalline phases. We believe that $\mathrm{TeO}_{2}-\mathrm{Nb}_{2} \mathrm{O}_{5}-\mathrm{TiO}_{2}$ glasses might be good host for the laser materials with rare-earth doped ions.

\section{Acknowledgments}

The authors gratefully acknowledge the Scientific and Research Council of Turkey (TÜBITTAK) under the projects numbered 108T239 and 108T694 for the funding of the Research Laboratory. The authors also thank Ress. Asst. Mustafa Durgun for providing the FT-IR spectrophotometer in the Department of Chemistry, Harran University.

\section{References}

[1] R. Balda, J. Fernandez, S. Garcia-Revilla, J.M. Fernandez-Navarro, Opt. Expr. 15, 6750 (2007).

[2] A. Sennaroğlu, İ. Kabalci, A. Kurt, U. Demirbas, G. Özen, J. Lumin. 116, 79 (2006).

[3] G. Wang, J. Zhang, S. Dai, J. Yang, Z. Jiang, Phys. Lett. A 341, 285 (2005).

[4] J. Li, Z. Sun, X. Zhu, H. Zeng, Z. Xu, Z. Wang, J. Lin, W. Huang, R.S. Armstrong, P.A. Lay, Opt. Mater. 25, 401 (2004).

[5] J.S. Wang, E.M. Vogel, E. Snitzer, Opt. Mater. 3, 187 (1994).
[6] S. Rada, M. Cule, M. Rada, T. Rusu, E. Cule, J. Alloys Comp. 490, 270 (2010).

[7] J. Ozdanova, H. Ticha, L. Tichy, J. Non-Cryst. Solids 353, 2799 (2007).

[8] M.M. Ahmad, El S. Yousef, El S. Moustafa, Physica B 371, 74 (2006).

[9] M. Udovic, P. Thomas, A. Mirgorodsky, O. Masson, T. Merle-Mejean, C. Lasbrugnas, J.C. ChamparnaudMesjard, T. Hayakawa, Mater. Res. Bull. 44, 248 (2009).

[10] J. Lin, W. Huang, Z. Sun, CS. Ray, D.E. Day, J. NonCryst. Solids 336, 189 (2004).

[11] R. Stegeman, C. Rivero, K. Richardson, G. Stegeman, P. Delfyett Jr., Y. Guo, A. Pope, A. Schulte, T. Cardinal, P. Thomas, J.C. Champarnaud-Mesjard, Opt. Expr. 13, 1144 (2005).

[12] T. Hayakawa, M. Hayakawa, M. Nogami, P. Thomas, Opt. Mater. 32, 448 (2010).

[13] İ. Kabalci, G. Özen, M.L. Öveçoğlu, J. Raman Spectrosc. 40, 272 (2009).

[14] B. Öz, M.L. Öveçoğlu, I. Kabalci, G. Özen, J. Eur Ceram. Soc. 27, 3239 (2007).

[15] S. Blanchandin, P. Thomas, P. Marchet, J.C. Champarnaud-Mesjard, B. Frit, J. Alloys Comp. 347, 206 (2002).

[16] M.A. Villegas, J.M. Fernandez, J. Navarro, J. Eur. Ceram. Soc. 27, 2715 (2007).

[17] G. Wang, J. Zhang, S. Dai, L. Wen, J. Yang, Z. Jiang, J. Mol. Struct. 750, 1 (2005).

[18] R.A.H. El-Mallawany, Tellurite Glasses Handbook, CRC Press, Boca Raton 2000.

[19] M.A.P. Silva, Y. Messaddeq, V. Briois, M. Poulin, F. Villain, S.J.L. Ribeiro, J. Phys. Chem. Solids 63 , 605 (2002).

[20] A.P. Mirgorodsky, TM. Mejean, J.C. Champarnaud, P. Thomas, B. Frit, J. Phys. Chem. Solids 61, 501 (2000).

[21] S. Blanchandin, P. Thomas, P. Marchet, J.C. Champarnaud-Mesjard, B. Frit, J. Alloys Comp. 347, 206 (2002).

[22] R. Agaki, K. Handa, N. Ohtori, A.C. Hannon, M. Tatsumisago, N. Umesaki, J. Non-Cryst. Solids 256257, 111 (1999).

[23] J.C. Champarnaud-Mesjard, S. Blanchandin, P. Thomas, A. Mirgorodsky, T.M. Mejean, B. Frit, J. Phys. Chem. Solids 61, 1499 (2000).

[24] D.K. Durga, PY. Reddy, N. Veeraiah, J. Lumin. 99, 53 (2002).

[25] D. Lezal, J. Bludska, J. Horak, A. Sklenar, S. Karamazov, M. Vlcek, Phys. Chem. Glasses 43, 296 (2002).

[26] Z. Pan, S.H. Morgan, J. Non-Cryst. Solids 210, 130 (1997).

[27] G.S. Murugan, Y. Ohishi, J. Non-Cryst. Solids 351 , 364 (2005).

[28] D. Tatar, M.L. Ovecoglu, G. Ozen, Ceram. Int. 38, 1927 (2003). 